\title{
Epoxy Based Nanocomposite Material for Automotive Application-A Short Review
}

\author{
Md. Nazmus Sakib1,2, and AKM Asif Iqbal ${ }^{1}$ \\ ${ }^{1}$ Faculty of Manufacturing and Mechatronic Engineering Technology, Universiti Malaysia Pahang, 26600 Pahang, Malaysia \\ 2Department of Electrical \& Electronic Engineering, Faculty of Science \& Engineering, International Islamic University Chittagong (IIUC), \\ Chittagong-4318, Bangladesh
}

\begin{abstract}
The automotive industry is a rapidly growing sector of the economy of most countries. Due to consumer and world population growth, the continuous necessity of a better, safe, and economical transportation approach increases with low emission. Researchers and producers face many challenges in the automobile industry for environmental issues, greenhouse gas emissions, boosting the fuel economy, weight minimization, and maintaining modern automobiles' safety and performance. Several strategies towards developing innovative materials have been introduced to address the challenges and replace heavy metal with lightweight polymer composite. Lightweight polymer composite materials offer great potential for increasing vehicle efficiency, decreased fuel consumption, reduced vehicle weight, and corrosion avoidance perspective than heavier materials. Epoxy as a thermoset polymer added with filler material produces nanocomposite material, which increased mechanical, chemical, electrical, and thermal properties, high compatibility, low cost, and shrinkage played significant roles in this regard. This article summarises the material selection process and the application of lightweight polymer composite materials, especially epoxy nanocomposite material, in the automotive industry.
\end{abstract}

ARTICLE HISTORY

Received: $18^{\text {th }}$ Feb 2021

Revised: 14 ${ }^{\text {th }}$ Sept 2021

Accepted: 21 $1^{\text {th }}$ Sept 2021

KEYWORDS

Epoxy nanocomposite;

Automotive;

Application;

Lightweight materials

\section{INTRODUCTION}

In this $21^{\text {st }}$ century, maintaining a sustainable ecosystem is a significant challenge for industrialists and researchers. Greenhouse gas (GHG) emissions from personal and passenger cars are the prime issues to design a new vehicle that meets the social and environmental demand for safety and comfort standards [1], [2]. The high use of fossil fuels in the automobile produces massive $\mathrm{CO}_{2}$ and cause climatic change. With an increase in the world population, transportation demand frequently increases due to their daily activities. Therefore, automobiles could not be stopped but can be controlled by developing regulation criteria. To maintain sustainability in the environment and consumer's satisfaction, industries and researchers focused on green technology to overcome GHG emissions. The most effective alternative to sustaining daily demand, environmental protection, and fuel-efficient material for automotive vehicles is a lightweight polymer composite [3]. Researchers and industries combined work to overcome the environmental issue. Polymer-based composite has drowned their attention due to its multi-functional properties, ease to produce, low cost, high tensile strength, corrosion resistance, damage and fatigue resistance and noise-damping properties [4]. Thermoplastics and thermosetting are polymers where thermoplastic can be re-melted after curing, but thermosetting could not be due to a higher melting point. Epoxy is a prominent thermosetting polymer widely used for its outstanding mechanical, thermal, electrical (excellent insulator), anti-corrosive, high compatibility with filler materials and lightweight properties [5], [6].

A wide variety of filler and nanofiller like- graphene oxide, GNP, carbon nanotube, nanofibres, nano clay, glass, titanium can be reinforced into the epoxy matrix to produce nanocomposites for painting, coating, automobile, electronics, aerospace, marine, tooling, sports and biomedical applications [7]-[13]. To enhance environmental degradation, epoxybased nanocomposites have been used in the automobile industry as a bumper beam [14], headliners, door panels, package trays, seatbacks, interior parts [15], dashboards and power transmission drive shafts [16]. Davoodi et al. [14] reported that 250 million barrels of fossil fuel could be saved by reducing vehicle weight by $25 \%$. In contrast, about $10-30 \%$ of car weight can be decreased by using epoxy-based composite materials. Corporate Average Fuel Economy (CAFE) claimed, within 2025 , automobile fuel effectiveness will be improved $6-8 \%$ by $10 \%$ of weight reduction[17]. It will help to reduce $\mathrm{CO}_{2}$ discharges and enhance a healthy and green environment for sustainable development. This review focuses on lightweight automotive materials, especially epoxy-based composite materials, their function, and applications.

Attaining a sustainable environment by reducing $\mathrm{CO}_{2}$ emissions is the main challenge for the automotive industry. By replacing heavy materials of automobiles with lightweight polymer composite materials improve fuel efficiency, which leads to reduced $\mathrm{CO}_{2}$ emission. Therefore, it is essential to review the current materials and composites used in the automobile industry. However, there has been no review article dealing specifically with epoxy-based composites in automobiles, which is the subject of this paper. Traditional and epoxy-based composite materials of automobiles have been reviewed. Besides that, the use of lightweight materials in automobiles reduces fuel consumption, and $\mathrm{CO}_{2}$ emission 
have been correlated. To the best of our knowledge, we believe this study covers most of the important publications relating to the topic to date.

\section{EPOXY NANOCOMPOSITE}

Epoxy resin was first discovered in the USA by Switzerland scientists Dr Castan and Dr Greenlee in1936. Epoxy is one of the most adjustable and commonly sold high-performance materials [13]. Because of its flexible nature, epoxy replaces many traditional materials. For most transportation industries, epoxy-based polymers have substituted heavy metals. Epoxy resins are thermosetting polymers and are characterised as a methyl group over one epoxy group that reactions with an additive (curing agent) throughout the epoxy coating group to form a long chain, three-dimensional network [18]. Epoxy is brittle and vulnerable to crack formation because of its crosslinking structure, limiting its engineering applications. Reinforcing filler material into the epoxy matrix to produce epoxy-based nanocomposite material has been shown efficient performance in various structural and industrial [19]. Epoxy-based materials are frequently used with their exceptional mechanical properties, resistance to solvents, thermal conductivity, crosslinking behaviour, and ease of processing properties [20]. Applications of epoxy and its nanocomposites include automobile, aerospace, buildings, marine, electrical and computer devices, sports materials, biomedical equipment, adhesives, thermal management systems, industrial tooling, paints and coatings, and other general consumer products [7]. Figure 1 shows the chemical structure of epoxy and its few applications.
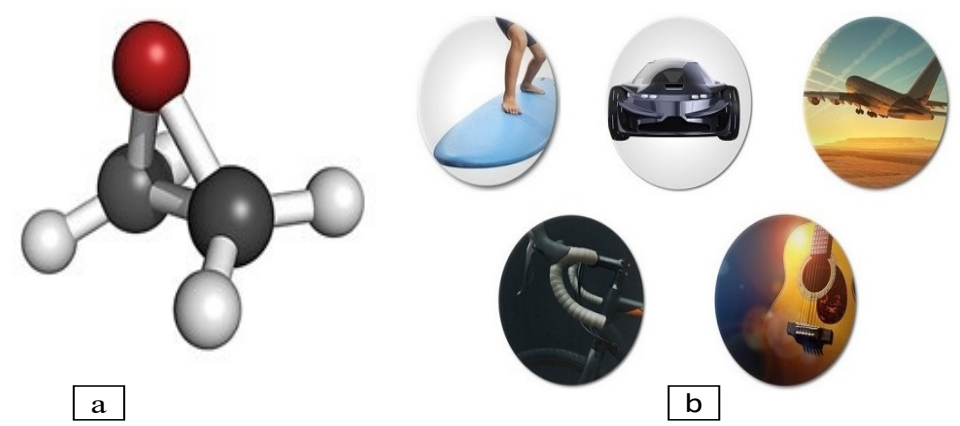

Figure 1. (a) Chemical structures of epoxy or oxirane ring, and (b) application of epoxy-based composite material. Reproduced from [21], [22].

Epoxy-based composites material showed high strength, good mechanical, thermal, and electrical properties, corrosion resistance. The commonly used epoxy-based composite materials for automotive application are described as the following Table 1 .

\section{Epoxy-Inorganic Composites}

Inorganic flakes enhance the epoxy matrix's mechanical properties. A combination of an inorganic filler and epoxy resin produces new composite materials that promote crack propagation resistance, excellent corrosion resistance, thermally insulation good processing and deformation thecnique[23]. These nanocomposites are suitable to use in automobiles, coating and anti-ageing [24].

\section{Epoxy-Carbon Fibre Nanocomposites}

Carbon fibres have very high mechanical, thermal, and electrical properties used as filler material, are integrated into the epoxy matrix to produce composite materials. Carbon fibre improves the epoxy matrix's adhesion while it is coated with proper sizing and solution[25]-[28]. Due to its excellent modules, strengths, and low densities, carbon fibrereinforced epoxy nanocomposites are widely used as substitutes for metals such as steel. The common use of carbon fibreepoxy nanocomposites is automotive, aerospace, and marine applications [29]-[31].

\section{Epoxy-Clay Nanocomposites}

A 2:1 layered silicate with sheets bearing negative charges composed of interlayer cations $(\mathrm{Na}+$ and $\mathrm{Mg} 2+$ ions $)$ is montmorillonite-based clay [7]. The agglomeration nature of clay while being mixed with polymer matrix showed degradation in wear resistance and mechanical properties. Substituting the inorganic $\mathrm{Na}+$ cations on the clay surface with the desired organic cations, specifically alkylammonium ions, is the most common way to solve this difficulty. Two types of morphology form when these surface-treated clays are incorporated into the host polymer matrix. One is intercalated other are delaminated/exfoliated nanocomposite constructions [32], [33]. The poor concentration of clay as filler into the epoxy matrix exhibit remarkable mechanical, thermal properties, flammability, and permeability compared to traditional macro/micro composites. The epoxy/clay composites' exhibit excellent properties due to their high interface/volume ratio and nanoscale measurement clay [34]. 


\section{Epoxy-Carbon Nanotube Nanocomposites}

Carbon nanotubes (CNTs) are built with substantially higher length-to-diameter ratios than those of any other material, giving them exceptional mechanical, electrical and thermal properties. Thus to boost the polymer concrete's efficiency, CNTs would be useful fillers [35], [36]. However, their implementation in this field has been restricted by the low miscibility and poor interfacial correlations of CNTs within epoxy matrices. Examples of widely used mechanical approaches are ultrasonic dispersing and high-shear mixing. Physical methods include the accumulation and/or glueing on CNT surfaces of polymers or surfactants, and chemical processes consist of nucleophilic covalent bonds on CNT surfaces of polymer chains, greatly enhancing intermolecular interaction among them and the epoxy matrix [37], [38]. A uniform distribution of aligned CNTs with desirable chemical interactions with the epoxy resins can achieve success for electrons and phonons. It provides a conductive pathway of the specific mechanical, thermal, and electrical behaviours shown by epoxy/CNT composites.[39], [40].

Table 1. Different epoxy/polymer nanocomposites with their properties and applications.

\begin{tabular}{|c|c|c|c|}
\hline Matrix & Filler & Properties and applications & Reference \\
\hline \multirow[t]{14}{*}{ Epoxy } & Carbon fibre & Adhesive, transportation, sporting & {$[58]-[60]$} \\
\hline & Clay & Absorbant for the pollutant, jewellery & {$[61]-[64]$} \\
\hline & & $\begin{array}{l}\text { Heat-resistant and flame retardant, increase the toughness of epoxy, } \\
\text { used in aerospace, defence, and automotive industry }\end{array}$ & \\
\hline & Carbone nanotube & $\begin{array}{c}\text { Coatings, adhesives, electronics, radiation shielding, } \\
\text { automotive/aerospace, textile }\end{array}$ & $\begin{array}{l}{[37],[65]-} \\
{[73]}\end{array}$ \\
\hline & Graphene/ & Aerospace, unmanned areal vehicle & {$[74]-[79]$} \\
\hline & graphite & $\begin{array}{l}\text { Antistatic, electronic industries, automotive structures, lightweight } \\
\text { material, rechargeable batteries, supercapacitor }\end{array}$ & \\
\hline & Titanium & $\begin{array}{l}\text { Corrosion and photostability, photocatalytic activity, skincare } \\
\text { products, nanomedicine, lithium-ion batteries, weather durability } \\
\text { with respect to their tendency to absorb ultra-violet waves }\end{array}$ & {$[80]-[83]$} \\
\hline & Glass fibre/ $\mathrm{ZnO}-$ & Hydrophilicity, optical transparency & {$[84]-[86]$} \\
\hline & $\mathrm{SiO} 2$ & Mirrors, window glass, and windshields of automobiles & \\
\hline & Inorganic & Dielectric, thermal insulation, and excellent corrosion resistance & {$[33],[87]$} \\
\hline & composite & Low cost, used fireproof panels, anti-ageing and ventilation ducts & \\
\hline & SWCNT/MWCNT & The aerospace industry, automobiles, military aircraft & [88] \\
\hline & GIN & Corrosion protection & [89] \\
\hline & Silver & Enhance electrical conductivity & [90] \\
\hline $\begin{array}{l}\text { Plastic } \\
\text { material }\end{array}$ & Carbon fibre & Fuels tank for buses & [91] \\
\hline Polymer & CNT & Lightweight, substitute for steel parts & {$[92]$} \\
\hline Rubber & $\begin{array}{l}\text { Silica Better, } \\
\text { Carbon Blac }\end{array}$ & Reduce inner friction, rolling resistance & \\
\hline \multirow[t]{5}{*}{ Polymer } & $\mathrm{TiO} 2, \mathrm{ZnO}, \mathrm{Cu}$ & Antistatic, antimicrobial & \\
\hline & Nanosheets & Improve engine lubrication & \\
\hline & Titania, $\mathrm{ZnO}$ & UV resistant, lightweight & \\
\hline & LDH & Flame retardant & \\
\hline & $\mathrm{SiO} 2$ & Anticorrosion & \\
\hline
\end{tabular}

\section{Epoxy-Graphene Nanocomposites}

Graphene has drawn considerable interest in the latest research innovations and structural industry due to its outstanding properties, geometrical shape, size, and exceptional arrangement of the atom. As a nanofiller, a small amount of graphene enhances the structural and functional properties of polymer nanocomposites [41]-[46]. Research has shown that graphene-polymer nanocomposites are novel materials commonly used for solar cell electrodes, transportation, sensors, biomedical devices and electromagnetic fields. Epoxy is a versatile material for its remarkable use in adhesive, automobiles, aerospace, electrical, and thermal application. Filler materials are incorporated to overcome crosslink and structural limitations of epoxy resin. Graphene showed good filler activity and overcame the hurdles. Epoxy/graphene nanocomposites are improving very fast with quality research innovations. Keyte et al. [37] and other researchers reported that graphene epoxy nanocomposite is an excellent lightweight material heaving magnificent mechanical, thermal and electrical properties, primarily used in aerospace, racing cars, marine and automotive industry [47]. Iqbal et al. [48] listed a few applications of graphene polymer nanocomposite in their recent review. Energy storage devices, solar cells, renewable energy [49], coating [50], electrical, electronics [51], industry for marine [52], and insulating materials[53] are some of the prominent applications of graphene and graphene-based epoxy nanocomposite materials [54].

\section{Epoxy- Titanium Nanocomposites}

Epoxy resin has enhanced mechanical, chemical, thermal, and electrical properties, low shrinkage, low cost, and high compatibility with different reinforcement materials, among other thermosetting and traditional thermoplastic polymers 
[12]. Epoxy resin has been reinforced with nanomaterials such as nanofibres, nano clays, carbon nanomaterials, and nanoparticles for automobile, aerospace, painting, sports, marine, biomedical, and electronic, tooling, and coating applications [7]. Although titanium is costly, it has retained its place in automobile manufacturing because of increasing concern for safety, weight reduction, and functional reasons. It has the best combination of strength to weight ratio and corrosion resistance properties more than any known metal in the world. Like metals such as calcium, cobalt, zirconium, iron, tin, cerium, and hafnium, titanium can crystalise in different crystal structures. At low temperature, a hexagonal closed packed structure known as $\alpha$ titanium is stable, while at a high temperature beyond transition temperature, a bodycentred cubic structure known as $\beta$ titanium is regular. These properties make titanium a suitable material for epoxy matrix reinforcement adapted for various applications [55].

\section{Glass Fibre Reinforced Epoxy}

A composite material system consisting of the plastic resin matrix, glass fibre reinforcement and other additives is a glass fibre reinforced composite system. A glass fibre composite is a composite material consisting of a plastic resin matrix, glass fibre reinforcement and other additives. The glass-enhanced composites are lightweight and can be manufactured as rounded, ribbed and corrugated. The glass-fibre materials are lighter than steel and aluminium [56]. Better surface quality and aerodynamics help to the reduction of weight, making it useful for the development of bumpers, boat hulls, small aircraft, fighter aircraft, and similar devices [57].

\section{MATERIALS USED IN THE AUTOMOTIVE INDUSTRY}

To make vehicles, different materials are used. Steel, aluminium, copper, magnesium, carbon fibre and polymer composite are the key material used for manufacturing vehicles, parts, and accessories, including future developments. There are numerous prime factors for material selection, particularly for the automobile body, including chemical, thermal or mechanical resistance, simplicity of production, and stability [93]. In automotive production, sustainability is a significant concern that requires factoring in the expenses involved with the entire life, as well as manufacturing, running and dumping costs. In the future, polymer nanocomposites will have significant advantages over steel in car production. Polymer composites have been used to manufacture lighter vehicles that are also fuel-efficient. Composite materials are mainly the combination of matrix material (epoxy resin, polymer) and filler material (GO, carbon fibre, glass, clay, CNT) that provides improved materials properties [93]. In terms of strength and stiffness, carbon fibre composites are just as good or better. Like steel or aluminium, they also do not rust or corrode, and by decreasing vehicle weight, they will significantly improve vehicle fuel economy.

The problem with today's composites is that they have been manufactured where the cost is not so vital for aerospace applications. Therefore, if we want to select materials with these attributes, the first option is steel. There have been many developments in iron and steel over the past few years that have made steel lighter, more powerful, more rigid, and enhanced other mechanical properties. Car bodies, frames, wheels, engines and many more components (doors, hoods, hatchbacks) are included in the applications [93]. The use of aluminium in the automotive sector has risen dramatically in recent years due to its high specific energy absorption, low density and good strength. The latest findings have shown that steel replacement can achieve up to $50 \%$ aluminium weight savings for white bodies. Another promising lightweight metal in automotive technology is magnesium which is 33\% lighter than aluminium and $75 \%$ lighter than iron parts made of steel/cast iron [93]. There are distinct advantages for magnesium alloys over aluminium, including the improved manufacturing process, higher die life and quick crystallisation. Moreover, components of magnesium have better machinability. Figure 2 illustrates different materials distribution in the automobile. Existing materials such as metals, composites, and others used in the automotive industry are listed below.

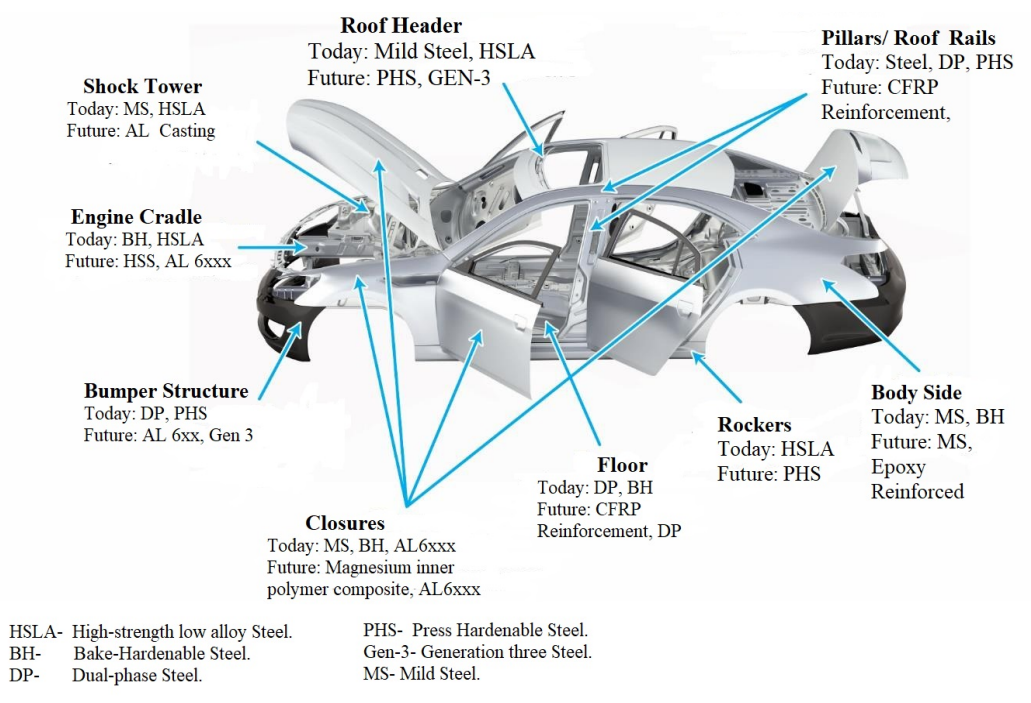

Figure 2. Materials used in an automobile. Reproduced with permission from [94]. 


\section{Steel}

Over the past few years, modern iron and steel technologies have seen tremendous growth and are regularly used in all automakers' new models and redesign. The steel industry and suppliers of equipment invest a lot in technology. In the automotive field, steel uses involve automobile bodies, chassis, engines, wheels and several other parts. Weight loss plus parallel improvements in strength, rigidity, and other features of structural efficiency are commonly seen in applications. Since the frame, chassis, engine and other engine and transmission parts made of ferrous materials form the bulk of a mass vehicle, many of these specifications include lightweight steel and iron technologies with possible replacements [95]. Since they are the preferred material, mass reduction is important by advanced iron and steel usage (ferrous materials). These are low-cost components with wide experience and industry expertise (approximately $86 \%$ of the total weight of the car is contributed by steel and cast iron) [95].

\section{Magnesium}

Magnesium is a promising lightweight material that is $33 \%$ lighter than aluminium and $75 \%$ lighter than steel. Magnesium is unparallel for its corrosion resistance, thermal conductivity, lighter weight properties, but it has some drawbacks such as lower hardness, tensile, creep and fatigue strength that requires a special arrangement for automotive application. This should be observed, though, that this suitable teasing and supports can overcome the disadvantages of modulus and strength [95]. Magnesium alloys have unique advantages against aluminium, which shouldn't be overlooked, despite the above issues, including improved performance, longer life, and quicker solidification because of less latent heat. Magnesium and its alloy components have good machinability, dimensionality and surface quality and smaller draught angles. By reducing dross and limiting the inclusion of gas and oxide while allowing a more uniform melt temperature, the ability of the magnesium to be hot chamber die cast would reduce casting scrap [95]. Magnesium derivatives are used as chassis, steering, body, instrument panels and transmission system casings in the automobile and aerospace industry [96]-[99].

\section{Aluminium}

In the automobile industry, the use of aluminium and its alloys has been increasing significantly. Aluminium and its derivatives have been employed in numerous car components such as engine blocks, resulting in significant weight reduction [100]. Casting aluminium is frequently used in automobiles. The maximum per cent of automotive power trains (piston $100 \%$, cylinder head $75 \%$ and intake manifold $85 \%$ ) are made of aluminium alloys. Other parts like the chassis, brake and suspension system used around $40 \%$ casting aluminum [101]. In heat shields, airbag housings, bumper reinforcements, seat frames, pneumatic devices, side-impact panels, sumps, to name only a few, wrought aluminum is also finding applications [102]. The use of aluminium in heat exchangers was also significant.

\section{Polymer and Composites}

Composite materials may hopefully have huge advantages over steel in automotive manufacturing. Composites are found to promote lighter, stronger, and more fuel-efficient automobiles. Composite material is the combination of filler (such as carbon, CNT, GO, clay, glass) and a matrix material (epoxy, phenolics, nylon, polypropylene, acrylics) which improved properties rather than their single materials. Like steel or aluminium, they also do not rust or corrode. Oak Ridge National Laboratory (ORNL) could significantly boost vehicle fuel efficiency by decreasing the weight of the vehicle by as much as $60 \%$ [103]. Set belts and sets covers are mostly made by polyester composite[104].

\section{MATERIAL SELECTION FOR AUTOMOBILE}

Figure 3 represent the Ashby chart for materials tensile strength vs density. The chart has shown different materials like metals, plastic, polymer composite, alloys. As shown in the diagram, many plastics and polymer composites are significantly less dense than most metals and alloys, offering equivalent tensile strengths. These data highlighted the fundamental physical advantage offered over metallic automotive materials by several plastics and polymer composite materials: higher strength-to-weight ratios that allow car manufacturers to provide lightweight automobiles while preserving safety and performance[14]. 


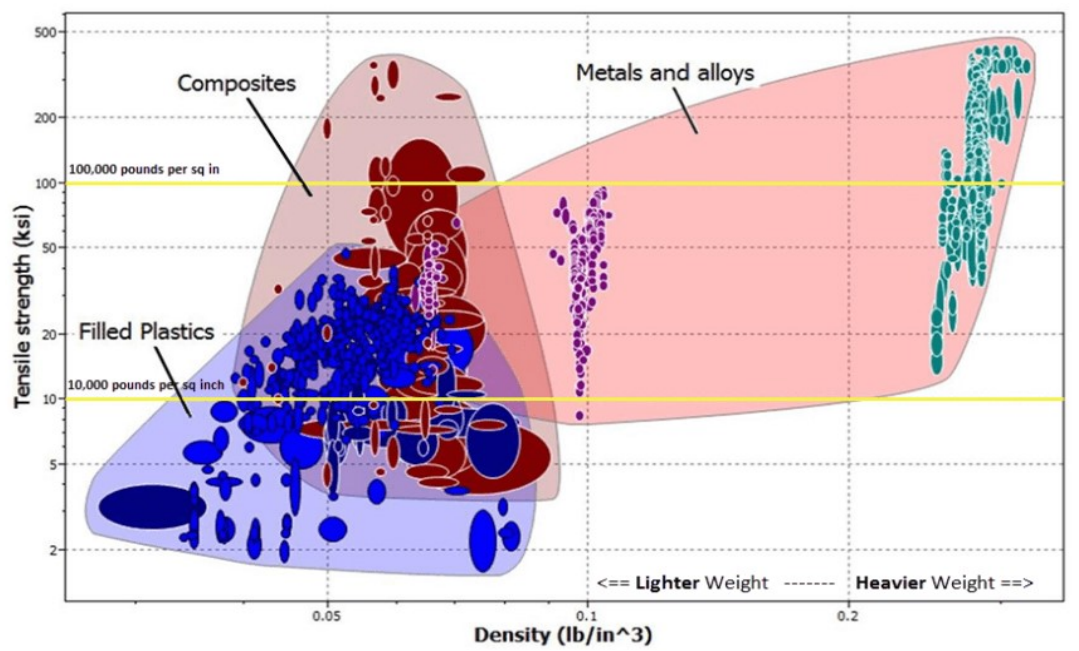

Figure 3. Automotive materials selection through tensile strength vs density M.F. Ashby chart [103], [105].

\section{AUTOMOTIVE PARTS MADE BY EPOXY / POLYMER NANOCOMPOSITE}

The types of materials used for the manufacture of these new automotive applications tend to be dramatically altered. The new automotive industries have pushed extensively towards the implementation of lightweight goods. This reform can be understood to increase the need to decrease the vehicle's weight to improve fuel efficiency. According to CAFE 2025 regulations, the deployment of lightweight in cars is sought by numerous car manufacturers, as a $10 \%$ reduction in weight will bring about a 6-8 \% improvement in fuel economy. Plan optimisation, material replacement, and component consolidation are the variables that influence the lightweight property of the automobile. In the instrument panels, thermoplastic polymers, sealing, elastomers benches, belts, gaskets, adhesives, and tires such as PE, PP, and polyamide (PA) were used. Natural fibre-reinforced composite is currently being manufactured by automakers to minimise vehicle weight and $\mathrm{CO}_{2}$ footprint by different elements of the vehicles [106].

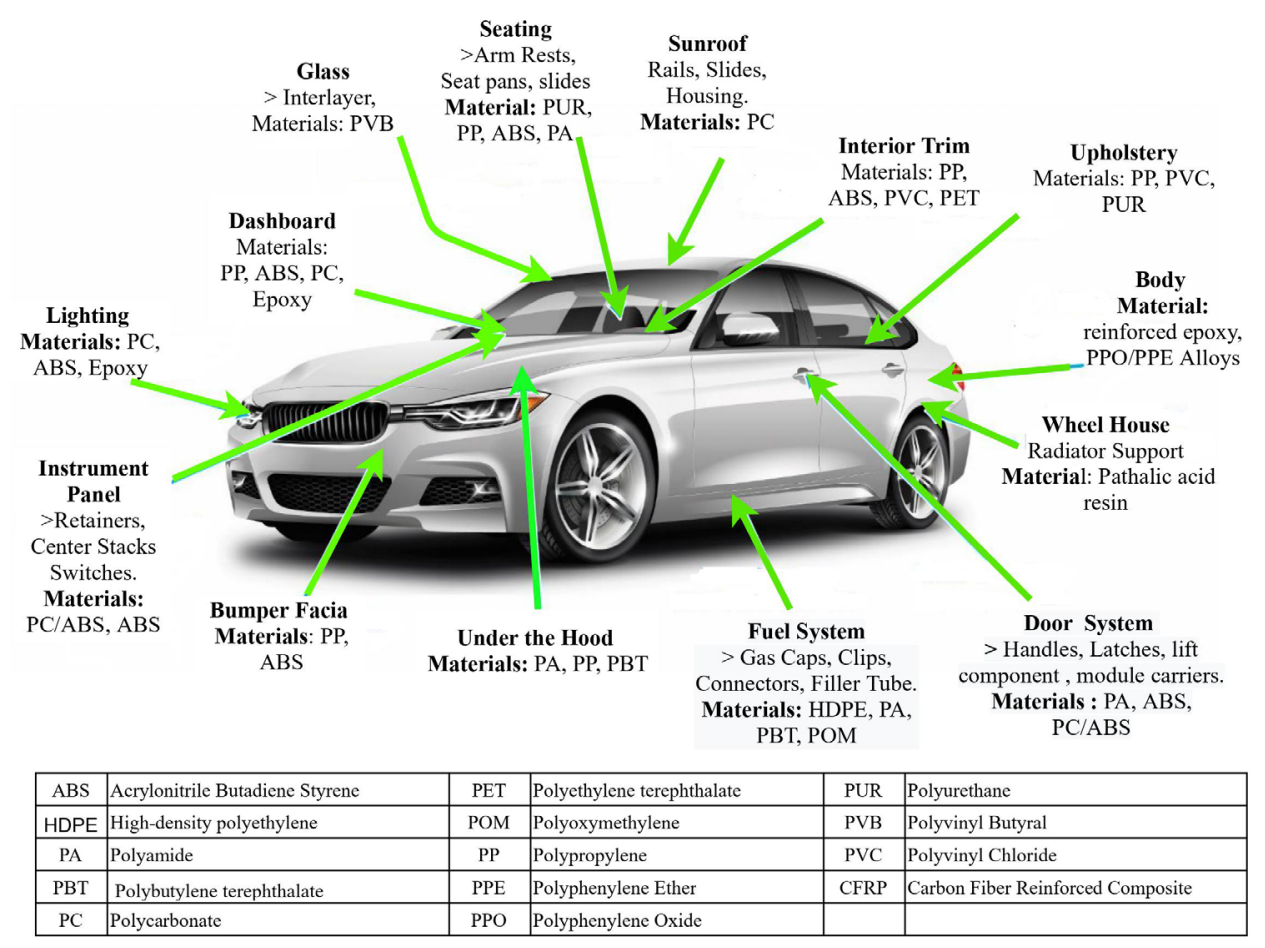

Figure 4. The most important part of an automobile where polymer composite used. Reproduced with permission from [63], [94].

\section{Brake System}

The automobile brake system operates on the principle of conversion of kinetic energy into heat energy. The brake pad and brake disc have individual specifications for an accurate brake device, namely a high friction coefficient between the position and the disc and thermal stability at high temperatures. Potassium titanate particles have been identified as a suitable replacement. On the other hand, a phenolic resin used over the years as a binder material in brake pad decompose 
at high energy braking conditions has low impact strength and is brittle. Titanium alloys are used for brake sealing washers, brake guiding pins, and brake pad carrier plates [107]. Crab shell powder based brake pads are more suitable studied by Singaravelu et al. [108], modified epoxy resin has been used to overcome this shortcoming in the brake pad manufacturer [109].

\section{Coating and Paints}

Many automobile parts require a protective coating to enhance their appearance and durability. The uppermost coat layer ranges between 5 and $50 \mu \mathrm{m}$ in thickness. This layer protects the inner layers and substrates from the degrading effects of chemical and UV rays. It can also provide scratch and blemish resistance. It has been identified that the exterior body paint's scratch performance is the most crucial phenomenon that customers are concerned about [110]. Epoxy has been widely used as a protective material for many types of surfaces because of its chemical and corrosion resistance, suitable adhesion property, and excellent thermal and mechanical properties [89]. Recently, Lei et al. [111] demonstrated hydrophobic and transparent coating based on a glass substrate's developed epoxy structure. The scratch resistance performance of the layer was appreciable. It was observed that $5 \%$ of epoxy concentration displayed a maximum contact angle of approximately $113^{\circ}$. Also, the surface roughness increased as the attention of the epoxy coating increased. Furthermore, the layer was observed to reduce the rate of crack propagation. It also observed that the inclusion of nanoparticles, such as silicon dioxide and titanium dioxide, can improve the epoxy coating's strength. The most recent advancement in automobile paints and coatings is polymer matrix-based superhydrophobic nanocoatings [112]. They have exceptional hydrophobic properties where epoxy was utilised for this purpose. It has been observed that the introduction of nano-fillers such as $\mathrm{TiO}_{2}$ can result in superhydrophobic Nanocoatings with unique combined properties such as anti-corrosion, anti-bacterial, anti-icing, antifogging, self-cleaning, and anti-fouling properties [113].

\section{Lightweight Automotive Parts}

Achieving lightweight is key to achieving fuel economy. The appreciable effort has been directed towards the replacement of conventional material with lightweight parts in the automotive industry. Titanium and epoxy resin have played a significant role in this regard. Sardou et al. [114] reported light composite coil springs using epoxy resin reinforced with E-glass fibre. The extended fatigue life was achieved through a unique positioning of the reinforcing fibre. It was observed that a weight reduction of about $75 \%$ could be obtained with the application of composite coil spring.

\section{Glass Epoxy Nanocomposite}

Automobile windows, headlights, and mirrors have glass components. Quite often, water droplets, dirt, oil, and other particles that cling onto the glass and the presence of cracks or scratches cause light either from the sun or other vehicles falling on them to scatter, thereby creating glare. Glare can lead to accidents. Therefore glasses used for automobile headlights, windows, and mirrors require some unique features such as antifogging, anti-reflecting, self-cleaning, UV shielding, transparent, scratch-resistant, impact strength and water repellant properties. Epoxy-based coating and titanium dioxide nanoparticles have been utilised by various researchers to improve the stuff mentioned above of glasses used in automobile windows, headlights, and mirrors. The antifogging property effect of $\mathrm{TiO}_{2}$ nanoparticles on glass surfaces is based on capillary action. They make such bodies super hydrophilic with a contact angle that is less than $5^{\circ}$. Hence there is increased water absorption and spreading of water droplets, which reduces the scattering of light [115], [116]. The epoxy coating improves the strength of a glass surface by filling flaws on glass surfaces. As a result of this, there is reduced crack length, which can produce healing stresses [117].

Nowadays, the safety regulations of car drivers lead to rearview mirrors to obtain a good view at dawn and dusk. This can be accomplished by equipping glasses with electrochromic properties with a practical layer composite. The optical properties of the glasses fitted with this technology will be modified by applying a specific voltage that moves the intermediate layer charges. Colour centres formed by ions on the electrodes will consume the light rays. A small amount of light would, as a consequence, be reflected[118].

\section{Instrumental Panel}

In modern automobiles, the instrumental panel plays a critical role, adding to the car's structure, offering an attractive look consisting of a velocity meter, an infotainment system (provides climate control transfer base passage), an odometer, tachometer, and airbag provision. Faurecia is a significant supplier consisting of $20 \%$ of the vehicle weight for the design and production of multiple OEMs such as General Motors, Volvo, PSA, Ford, Nissan, and Renault. Biocomposites such as jute coir, flax, and sisal have been deemed impossible to use regular plastics to minimise weight with greater strength and potentially improve fuel economy in today's era [119].

\section{Fuel Tanks.}

The fuel tanks are the main component of the vehicle where the fuel is stored to produce power, and the fuel tanks typically have an average capacity of about 50 litres. To protect the fuel from evaporating, tanks should be airtight and have adequate ventilation [106]. Federal Motor Vehicle Safety Standard (FMVSS 301) replaced sheet steel with polymer composites to avoid a severe accident due to fuel leakage to improve properties such as high corrosion resistance, greater design versatility, and enhanced safety lower cost [120], [121]. Figure 5 shows the plastic and polymer composite used 
in different specific automotive parts. It is clear that light weight polymer composite materials plays important role to replace heavy materials.

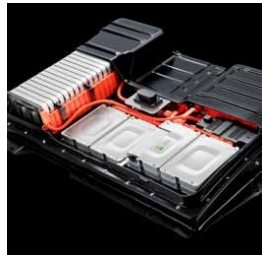

Battery Cover

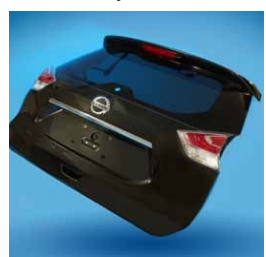

Liftgate

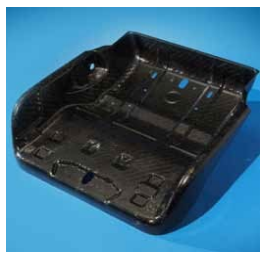

Seat Pan

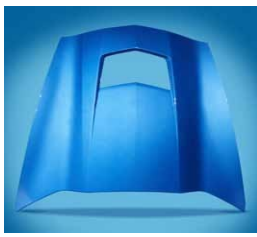

Hood

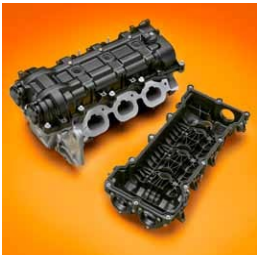

Valve Cover

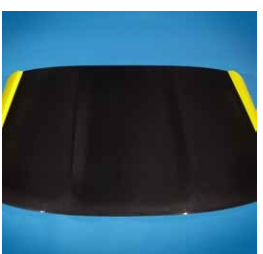

Roof Assembly

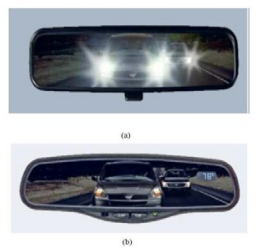

Anti-glare rear mirrors

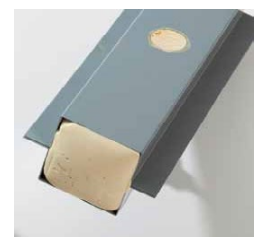

Foam Filled Door Frame

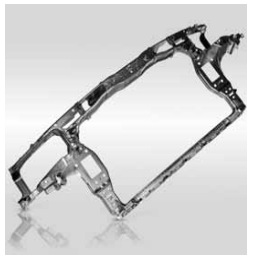

Front end Structure

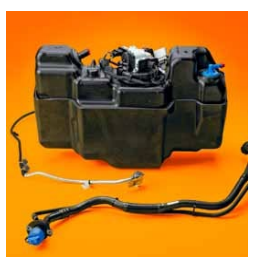

Fuel Tank

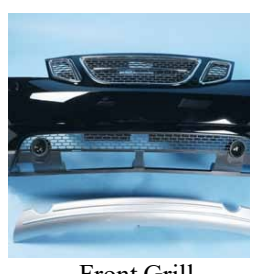

Front Grill

Figure 5. Plastic and polymer composite used in different automotive parts. Reproduced from [105], [118].

\section{EPOXY NANOCOMPOSITE- A BREAKTHROUGH IN AUTOMOBILE}

The worldwide market of automotive polymer composites was valued at USD 6.40 billion in 2016 and is projected to hit USD 11.62 billion by 2025, expanding over the forecast period at an annual CAGR of 6.8\%, shown in Figure 6 [122]. The industry is defined by the large-scale development of automobiles and the strict regulations imposed in the automotive sector. The auto industry faces difficulties aligning its manufacturing or assembly processes with enhanced material properties and creative product design, especially for large-volume production facilities. While aluminium and steel are more effective in reducing a vehicle's weight, both aluminium and steel will theoretically outperform high-performance FRP composites. Some of the factors likely to hinder market growth are the high cost of reinforcing materials, high manufacturing costs, expensive recycling processes, and the absence of mass production methods. Some factors expected to cause manufacturers to opt for backward integration in the supply chain are increased demand for fuel-efficient vehicles and rising lightweight automotive components. Increased involvement across the supply chain is expected to reduce the time needed to process raw materials into finished goods, which is likely to add to the cost advantage. To respond to rising market demand, automotive composite manufacturers expand their production capacities and concentrate on improving infrastructure. In the automotive industry, epoxy resin has been used as a structural glue for over 30 years, replacing the need for welding.

Car manufacturers commonly favour it due to mechanical efficiency, heat resistance, and metal adhesion. These characteristics help keep the body of the car from corrosion and other damage. As a coating for the car body, epoxy resins are used, usually by Cathodic Electro Deposition (CED). Figure 7 shows the current and future materials trends in the automotive industry as well as the epoxy and Polymer composite materials. By the increase of polymer composite or plastic lightweight materials in automobiles decrease its mass which enhances fuel efficiency [125]. Due to the decrease of fuel burnt, it produces less $\mathrm{CO}_{2}$ in the atmosphere, which protect the environment from the greenhouse effect. 


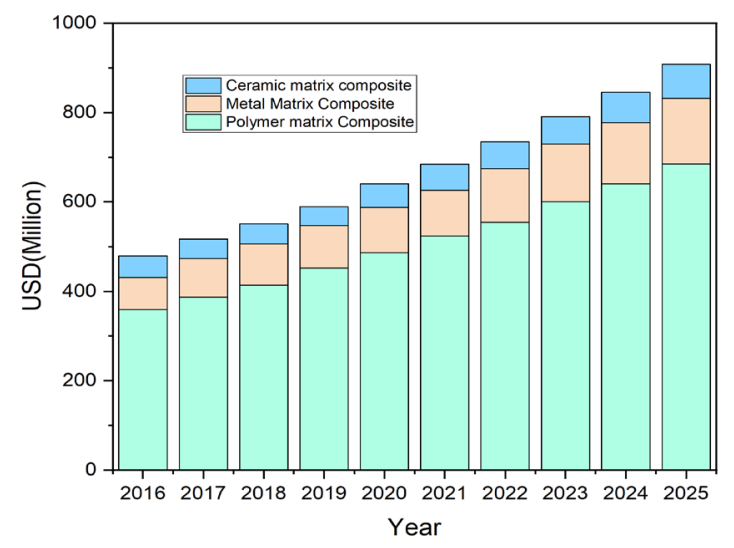

Figure 6. Revenue of US automotive polymer composite market up to 2025. Reproduced from [122], [123].

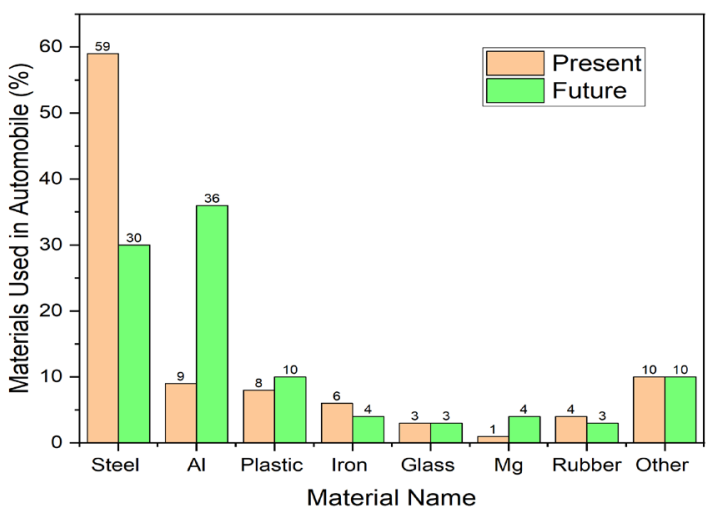

Figure 7. Present and future materials in an automobile. Reproduced figure from [124].

\section{CONCLUSION}

To ensure a green word, a sustainable environment, and reduce greenhouse gas (GHG) emissions is the main concern. Replacing heavy metals of automobile with lightweight polymer composite reduce vehicle weight and fuel consumptions. Reducing $\mathrm{CO}_{2}$ emissions through automobiles and industries is the aim of this study. To justify the study, the advancements made in epoxy-based nanocomposite material in the automotive industry and its wide variety of applications have been described. Some of the key findings from the study are

i. Polymer and plastic composite draw attention in the automotive industry due to their lightweight, corrosion resistance, high strength, thermal stability, and electrical insulation properties.

ii. Monolithic epoxy could not fulfil the automotive industry's required properties due to its crack propagation, brittle nature. The incorporation of suitable filler in the epoxy matrix produces excellent nanocomposite material in automobile parts, aeronautics, boats, bicycles, mirror, electronics, sensors, packaging, and biomedical.

iii. Introducing lightweight composite material in the automotive industry replaces heavy material and increases fuel efficiency, speed, and corrosion resistance.

iv. The use of polymer-based lightweight materials in the automotive industry reduce vehicle weight along with increasing fuel efficiency and reduction of $\mathrm{CO}_{2}$ emission. (CAFE) claimed, within 2025, automobile fuel effectiveness will be improved $6-8 \%$ by $10 \%$ of weight reduction.

\section{ACKNOWLEDGEMENT}

The authors are grateful to acknowledge Universiti Malaysia Pahang (UMP) for providing financial support under project no RDU190329 during this research work.

\section{REFERENCES}

[1] M. Pervaiz, S. Panthapulakkal, B. KC, M. Sain, and J. Tjong, "Emerging trends in automotive lightweighting through novel composite materials," Mater. Sci. Appl., vol. 07, no. 01, pp. 26-38, 2016, doi: 10.4236/msa.2016.71004.

[2] O. Akampumuza, P. M. Wambua, A. Ahmed, W. Li, and X.-H. Qin, "Review of the applications of biocomposites in the automotive industry," Polym. Compos., vol. 38, no. 11, pp. 2553-2569, Nov. 2017, doi: 10.1002/pc.23847.

[3] L. Miller, K. Soulliere, S. Sawyer-Beaulieu, S. Tseng, and E. Tam, "Challenges and alternatives to plastics recycling in the automotive sector," Materials, vol. 7, no. 8. Multidisciplinary Digital Publishing Institute (MDPI), pp. 5883-5902, 2014, doi: 10.3390/ma7085883.

[4] S. A. Akinlabi, O. S. Ogbonna, P. M. Mashinini, A. A. Adediran, O. S. Fatoba, and E. T. Akinlabi, "Titanium and epoxy for 
automobile application: A Review," in Proc. of the Eighth Intl. Conf. on Advances in Civil, Structural and Mechanical Engineering, 2019, vol. CSM 2019, pp. 48-58, doi: 10.15224/978-1-63248-170-2-09.

[5] H. Gu et al., "An overview of multi-functional epoxy nanocomposites," J. Mater. Chem. C, vol. 4, no. 25, pp. 5890-5906, 2016, doi: 10.1039/c6tc01210h.

[6] S. A. P. Pilla, R. K.Iyer;, H. Kazan;, and Srikanth, “Automotive applications of plastics_past, present, and future.," in Applied Plastics Engineering Handbook, 2nd ed., M. Kutz, Ed. William Andrew, 2017, pp. 651-673.

[7] F. L. Jin, X. Li, and S. J. Park, "Synthesis and application of epoxy resins: A review," J. Ind. Eng. Chem., vol. 29, pp. 1-11, 2015, doi: 10.1016/j.jiec.2015.03.026.

[8] S. Deng, L. Djukic, R. Paton, and L. Ye, "Thermoplastic-epoxy interactions and their potential applications in joining composite structures - A review," Compos. Part A Appl. Sci. Manuf., vol. 68, pp. 121-132, 2015, doi: 10.1016/j.compositesa.2014.09.027.

[9] N. M. Han et al., "Graphene size-dependent multifunctional properties of unidirectional graphene aerogel/epoxy nanocomposites," ACS Appl. Mater. Interfaces, vol. 10, no. 7, pp. 6580-6592, 2018, doi: 10.1021/acsami.7b19069.

[10] A. B. Irez, E. Bayraktar, and I. Miskioglu, "Fracture toughness analysis of epoxy-recycled rubber-based composite reinforced with graphene nanoplatelets for structural applications in automotive and aeronautics," Polymers (Basel)., vol. 12, no. 2, 2020, doi: 10.3390/polym12020448.

[11] J. Menjivar and K. Kirane, "Surfactant assisted dispersion of MWCNT's in epoxy nanocomposites and adhesion with aluminum," Polym. Test., vol. 82, no. September 2019, p. 106308, 2020, doi: 10.1016/j.polymertesting.2019.106308.

[12] N. Saba, M. Jawaid, O. Y. Alothman, M. T. Paridah, and A. Hassan, "Recent advances in epoxy resin, natural fibre-reinforced epoxy composites and their applications," J. Reinf. Plast. Compos., vol. 35, no. 6, pp. 447-470, 2016, doi: $10.1177 / 0731684415618459$.

[13] P. Mohan, “A critical review: The modification, properties, and applications of epoxy resins," Polym. - Plast. Technol. Eng., vol. 52, no. 2, pp. 107-125, 2013, doi: 10.1080/03602559.2012.727057.

[14] M. M. Davoodi, S. M. Sapuan, D. Ahmad, A. Ali, A. Khalina, and M. Jonoobi, "Mechanical properties of hybrid kenaf/glass reinforced epoxy composite for passenger car bumper beam," Mater. Des., vol. 31, no. 10, pp. 4927-4932, Dec. 2010, doi: 10.1016/j.matdes.2010.05.021.

[15] J. Holbery and D. Houston, "Natural-fibre-reinforced polymer composites in automotive applications," JOM, vol. 58, no. 11. Springer, pp. 80-86, Nov. 2006, doi: 10.1007/s11837-006-0234-2.

[16] M. A. Badie, E. Mahdi, and A. M. S. Hamouda, "An investigation into hybrid carbon/glass fibre reinforced epoxy composite automotive drive shaft," Mater. Des., vol. 32, no. 3, pp. 1485-1500, Mar. 2011, doi: 10.1016/j.matdes.2010.08.042.

[17] A. Patil, A. Patel, and R. Purohit, "An overview of polymeric materials for automotive applications," in Materials Today: Proceedings, Jan. 2017, vol. 4, no. 2, pp. 3807-3815, doi: 10.1016/j.matpr.2017.02.278.

[18] R. Rajan et al., "Modification of epoxy resin by silane-coupling agent to improve tensile properties of viscose fabric composites," Polym. Bull., vol. 75, no. 1, pp. 167-195, Jan. 2018, doi: 10.1007/s00289-017-2022-2.

[19] J. Wei, T. Vo, and F. Inam, "Epoxy/graphene nanocomposites - processing and properties: a review," RSC Adv., vol. 5, no. 90, pp. 73510-73524, 2015, doi: 10.1039/c5ra13897c.

[20] L. Guadagno et al., "Development of epoxy mixtures for application in aeronautics and aerospace," RSC Adv., vol. 4, no. 30, pp. 15474-15488, 2014, doi: 10.1039/c3ra48031c.

[21] "Epoxy resin: types, uses, properties \& chemical structure." https://omnexus.specialchem.com/selection-guide/epoxy-resinsa-to-z-technical-review-of-thermosetting-polymer (accessed July 01, 2020).

[22] G. Tesoro, "Epoxy resins-chemistry and technology," J. Polym. Sci. Polym. Lett. Ed., vol. 26, no. 12, pp. 539-539, Nov. 1988, doi: $10.1002 /$ pol.1988.140261212.

[23] K. Parvez et al., "Exfoliation of graphite into graphene in aqueous solutions of inorganic salts," J. Am. Chem. Soc., vol. 136, no. 16, pp. 6083-6091, Apr. 2014, doi: 10.1021/ja5017156.

[24] F. Mustata, N. Tudorachi, and D. Rosu, "Thermal behavior of some organic/inorganic composites based on epoxy resin and calcium carbonate obtained from conch shell of Rapana thomasiana," Compos. Part B Eng., vol. 43, no. 2, pp. 702-710, 2012, doi: 10.1016/j.compositesb.2011.11.047.

[25] S. H. Han, H. J. Oh, H. C. Lee, and S. S. Kim, "The effect of post-processing of carbon fibres on the mechanical properties of epoxy-based composites," Compos. Part B Eng., vol. 45, no. 1, pp. 172-177, Feb. 2013, doi: 10.1016/j.compositesb.2012.05.022.

[26] G. Y. Heo, Y. J. Yoo, and S. J. Park, "Effect of carbonisation temperature on electrical conductivity of carbon papers prepared from petroleum pitch-coated glass fibres," J. Ind. Eng. Chem., vol. 19, no. 3, pp. 1040-1043, May 2013, doi: 10.1016/j.jiec.2012.11.028.

[27] T. Brocks, M. O. H. Cioffi, and H. J. C. Voorwald, "Effect of fibre surface on flexural strength in carbon fabric reinforced epoxy composites," Appl. Surf. Sci., vol. 274, pp. 210-216, Jun. 2013, doi: 10.1016/j.apsusc.2013.03.018.

[28] M. Nazmus Sakib, A. A. Iqbal, and D. M. Nuruzzaman, "Mechanical characterisation of carbon fibre and graphene oxide reinforced epoxy hybrid composite," in Recent Trends in Manufacturing and Materials Towards Industry 4.0, Springer Singapore, 2021, pp. 155-161.

[29] I. Choi and D. G. Lee, "Surface modification of carbon fibre/epoxy composites with randomly oriented aramid fibre felt for adhesion strength enhancement," Compos. Part A Appl. Sci. Manuf., vol. 48, no. 1, pp. 1-8, May 2013, doi: 10.1016/j.compositesa.2013.01.003.

[30] J. Kim, J. Cha, B. Chung, S. Ryu, and S. H. Hong, "Fabrication and mechanical properties of carbon fibre/epoxy nanocomposites containing high loadings of noncovalently functionalised graphene nanoplatelets," Compos. Sci. Technol., vol. 192, p. 108101, 2020, doi: 10.1016/j.compscitech.2020.108101.

[31] H. Ahmad, A. A. Markina, M. V Porotnikov, and F. Ahmad, "A review of carbon fibre materials in automotive industry," IOP Conf. Ser. Mater. Sci. Eng., vol. 971, no. 3, p. 032011, Nov. 2020, doi: 10.1088/1757-899X/971/3/032011.

[32] F. L. Jin, K. Y. Rhee, and S. J. Park, "Surface treatment of montmorillonite on the thermal stabilities of bisphenol-A diglycidyl dimethacrylate nanocomposites," Mater. Sci. Eng. A, vol. 435-436, pp. 429-433, Nov. 2006, doi: 10.1016/j.msea.2006.07.071.

[33] D. Yu, M. Kleemeier, G. M. Wu, B. Schartel, W. Q. Liu, and A. Hartwig, "A low melting organic-inorganic glass and its effect on flame retardancy of clay/epoxy composites," Polymer (Guildf)., vol. 52, no. 10, pp. 2120-2131, May 2011, doi: 
10.1016/j.polymer.2011.03.033.

[34] E. Huttunen-Saarivirta, G. V. Vaganov, V. E. Yudin, and J. Vuorinen, "Characterisation and corrosion protection properties of epoxy powder coatings containing nanoclays," Prog. Org. Coatings, vol. 76, no. 4, pp. 757-767, Apr. 2013, doi: 10.1016/j.porgcoat.2013.01.005.

[35] J. Bae and J. Jang, "Fabrication of carbon nanotubes from conducting polymer precursor as field emitter," J. Ind. Eng. Chem., vol. 18, no. 6, pp. 1921-1924, Nov. 2012, doi: 10.1016/j.jiec.2012.05.004.

[36] H. R. Yu, J. G. Kim, J. S. Im, T. S. Bae, and Y. S. Lee, "Effects of oxyfluorination on a multi-walled carbon nanotube electrode for a high-performance glucose sensor," J. Ind. Eng. Chem., vol. 18, no. 2, pp. 674-679, Mar. 2012, doi: 10.1016/j.jiec.2011.11.064.

[37] I. Choi, J. G. Kim, I. S. Seo, and D. G. Lee, "Radar absorbing sandwich construction composed of CNT, PMI foam and carbon/epoxy composite," Compos. Struct., vol. 94, no. 9, pp. 3002-3008, Sep. 2012, doi: 10.1016/j.compstruct.2012.04.009.

[38] K. Sowichai, S. Supothina, O. uma Nimittrakoolchai, T. Seto, Y. Otani, and T. Charinpanitkul, "Facile method to prepare magnetic multi-walled carbon nanotubes by in situ co-precipitation route," J. Ind. Eng. Chem., vol. 18, no. 5, pp. 1568-1571, Sep. 2012, doi: 10.1016/j.jiec.2012.04.016.

[39] S. G. Prolongo, B. G. Meliton, G. Del Rosario, and A. Ureña, "New alignment procedure of magnetite-CNT hybrid nanofillers on epoxy bulk resin with permanent magnets," Compos. Part B Eng., vol. 46, pp. 166-172, Mar. 2013, doi: 10.1016/j.compositesb.2012.10.002.

[40] M. G. Kim, J. B. Moon, and C. G. Kim, "Effect of CNT functionalisation on crack resistance of a carbon/epoxy composite at a cryogenic temperature," Compos. Part A Appl. Sci. Manuf., vol. 43, no. 9, pp. 1620-1627, Sep. 2012, doi: 10.1016/j.compositesa.2012.04.001.

[41] T. Ramanathan et al., "Functionalised graphene sheets for polymer nanocomposites," Nat. Nanotechnol., vol. 3, no. 6, pp. 327331, 2008, doi: 10.1038/nnano.2008.96.

[42] E. N. Kalali, W. Guo, X. Wang, W. Xing, L. Song, and Y. Hu, "Effect of metal-based nanoparticles decorated graphene hybrids on flammability of epoxy nanocomposites," Compos. Part A Appl. Sci. Manuf., vol. 129, pp. 105694, 2020, doi: 10.1016/j.compositesa.2019.105694.

[43] P. Nanocomposites and M. Tarfaoui, "Effect of graphene nano-additives on the local mechanical behavior of derived," 2018, doi: 10.3390/polym10060667.

[44] M. Tabandeh-Khorshid, Ajay Kumar, E. Omrani, C. Kim, and P. Rohatgi, "Synthesis, characterisation, and properties of graphene reinforced metal-matrix nanocomposites," Compos. Part B Eng., vol. 183, no. November 2019, pp. 107664, 2020, doi: 10.1016/j.compositesb.2019.107664.

[45] A. Allahbakhsh, "Graphene-based advanced nanostructures," Handb. Graphene, vol. 8, pp. 471-493, 2019, doi: 10.1002/9781119468455.ch140.

[46] L. Guadagno et al., "Optimisation of graphene-based materials outperforming host epoxy matrices," RSC Adv., vol. 5, no. 46, pp. 36969-36978, 2015, doi: 10.1039/c5ra04558d.

[47] S. Nihtianov, Z. Tan, and B. George, "New trends in smart sensors for industrial applications-Part II," IEEE Transactions on Industrial Electronics, vol. 64, no. 12. Institute of Electrical and Electronics Engineers Inc., pp. 9592-9594, Dec. 01, 2017, doi: 10.1109/TIE.2017.2758038.

[48] A. A. Iqbal, N. Sakib, A. K. M. P. Iqbal, and D. M. Nuruzzaman, "Graphene-based nanocomposites and their fabrication, mechanical properties and applications," Materialia, vol. 12, no. July, pp. 100815, 2020, doi: 10.1016/j.mtla.2020.100815.

[49] H. Fang, Y. Zhao, Y. Zhang, Y. Ren, and S. L. Bai, "Three-dimensional graphene foam-filled elastomer composites with high thermal and mechanical properties," ACS Appl. Mater. Interfaces, vol. 9, no. 31, pp. 26447-26459, Aug. 2017, doi: 10.1021/acsami. 7b07650.

[50] X. Zhou et al., "Green modification of graphene oxide with phytic acid and its application in anti-corrosive water-borne epoxy coatings,” Prog. Org. Coatings, vol. 143, no. November 2019, pp. 105601, 2020, doi: 10.1016/j.porgcoat.2020.105601.

[51] W. A. de Heer, "The development of epitaxial graphene for 21st century electronics," Dec. 2010. [Online]. Available: http://arxiv.org/abs/1012.1644. [Accessed: Sep. 08, 2020].

[52] S. Kumar, S. K. Samal, S. Mohanty, and S. K. Nayak, "Recent development of biobased epoxy resins: A review," Polymer Plastics Technology and Engineering, vol. 57, no. 3. Taylor and Francis Inc., pp. 133-155, Feb. 11, 2018, doi: 10.1080/03602559.2016.1253742.

[53] A. Arshad, M. Jabbal, Y. Yan, and D. Reay, A review on graphene based nanofluids: Preparation, characterisation and applications, vol. 279. Elsevier BV, 2019.

[54] M. Raimondo, L. Guadagno, V. Speranza, L. Bonnaud, P. Dubois, and K. Lafdi, "Multi-functional graphene/POSS epoxy resin tailored for aircraft lightning strike protection," Compos. Part B Eng., vol. 140, pp. 44-56, May 2018, doi: 10.1016/j.compositesb.2017.12.015.

[55] M. Peters, J. Hemptenmacher, J. Kumpfert, and C. Leyens, "Structure and properties of titanium and titanium alloys." in Titanium and Titanium Alloys, C. Leyens and M. Peters, Eds. Wiley-VCH Verlag, 2005, pp. 1-36.

[56] K. Bijesh, "Effect of fibre loading on mechanical behavior of chopped glass fibre reinforced polymer composites," B.Tech thesis, National Institute of Technology Rourkela, India, 2010.

[57] A. John and S. Alex, "A review on the composite materials used for automotive bumper in passenger vehicles," Int. J. Eng. Manag. Res., vol. 4, no. 4, pp. 98-101, 2014.

[58] K. Friedrich, "Carbon fibre reinforced thermoplastic composites for future automotive applications," AIP Conf. Proc., vol. 1736, pp. 1-5, 2016, doi: 10.1063/1.4949575.

[59] K. Friedrich and A. A. Almajid, "Manufacturing aspects of advanced polymer composites for automotive applications," Appl. Compos. Mater., vol. 20, no. 2, pp. 107-128, 2013, doi: 10.1007/s10443-012-9258-7.

[60] "Materials \& amp; Processes: Composites fibres and resins," CompositesWorld. [Online]. Available: https://www.compositesworld.com/articles/composites-101-fibres-and-resins. [Accessed: Feb. 25, 2021].

[61] S. Gul, A. Kausar, B. Muhammad, and S. Jabeen, "Research progress on properties and applications of polymer/clay nanocomposite," Polym. - Plast. Technol. Eng., vol. 55, no. 7, pp. 684-703, 2016, doi: 10.1080/03602559.2015.1098699.

[62] O. Zabihi et al." "A technical review on epoxy-clay nanocomposites: Structure, properties, and their applications in fibre reinforced composites,” Compos. Part B Eng., vol. 135, pp. 1-24, 2018, doi: 10.1016/j.compositesb.2017.09.066. 
[63] M. Galimberti, V. R. Cipolletti, and M. Coombs, Applications of Clay-Polymer Nanocomposites, 2nd ed., vol. 5, no. C. Elsevier Ltd., 2013.

[64] M. Monsif et al., "Multi-functional epoxy/nanocomposites based on natural moroccan clays with high antimicrobial activity: Morphological, thermal and mechanical properties," J. Nanomater., vol. 2019, 2019, doi: 10.1155/2019/2810901.

[65] S. Faragi et al., "Mechanical properties of carbon nanotube- and graphene-reinforced Araldite LY/Aradur HY 5052 resin epoxy composites: a molecular dynamics study," J. Mol. Model., vol. 25, no. 7, 2019, doi: 10.1007/s00894-019-4085-5.

[66] V. Rezazadeh and M. Mohammadizadeh, "Effect of carbon nanotube and surfactant on processing, mechanical, electrical and EMI-shielding of epoxy composites," Int. J. Eng. Trans. B Appl., vol. 31, no. 11, pp. 1810-1815, 2018, doi: 10.5829/ije.2018.31.11b.02.

[67] Z. A. Ghaleb, M. Mariatti, and Z. M. Ariff, "Properties of graphene nanopowder and multi-walled carbon nanotube-filled epoxy thin-film nanocomposites for electronic applications: The effect of sonication time and filler loading," Compos. Part A Appl. Sci. Manuf., vol. 58, pp. 77-83, Mar. 2014, doi: 10.1016/j.compositesa.2013.12.002.

[68] A. Kausar, "Nanocarbon and macrocarbonaceous filler-reinforced epoxy/polyamide: A review," J. Thermoplast. Compos. Mater., 2020, doi: 10.1177/0892705720930810.

[69] S. Han et al., "Mechanical and electrical properties of graphene and carbon nanotube reinforced epoxy adhesives: Experimental and numerical analysis," Compos. Part A Appl. Sci. Manuf., vol. 120, no. February, pp. 116-126, 2019, doi: 10.1016/j.compositesa.2019.02.027.

[70] N. S. A. A. Bakhtiar et al., "New generation of hybrid filler for producing epoxy nanocomposites with improved mechanical properties," Mater. Des., vol. 91, pp. 46-52, 2016, doi: 10.1016/j.matdes.2015.11.081.

[71] Q. Rao, H. Huang, Z. Ouyang, and X. Peng, "Synergy effects of multi-walled carbon nanotube and graphene nanoplate filled epoxy adhesive on the shear properties of unidirectional composite bonded joints," Polym. Test., vol. 82, no. November 2019, p. 106299, 2020, doi: 10.1016/j.polymertesting.2019.106299.

[72] X. Zhang et al., "High-efficiency electromagnetic wave absorption of epoxy composites filled with ultralow content of reduced graphene/carbon nanotube oxides," Compos. Sci. Technol., vol. 189, pp. 108020, 2020, doi: 10.1016/j.compscitech.2020.108020.

[73] W. Lin, Q. Q. Shi, H. Chen, and J. N. Wang, "Mechanical properties of carbon nanotube fibres reinforced epoxy resin composite films prepared by wet winding," Carbon N. Y., vol. 153, pp. 308-314, Nov. 2019, doi: 10.1016/j.carbon.2019.07.002.

[74] Y. Wu et al., "The reinforcing effect of polydopamine functionalised graphene nanoplatelets on the mechanical properties of epoxy resins at cryogenic temperature," Polym. Test., vol. 58, pp. 262-269, 2017, doi: 10.1016/j.polymertesting.2016.12.021.

[75] V. K. R and S. K. Maharana, "Development of unmanned aerial vehicle by graphene based polymer matrix composites," Int. J. Recent Technol. Eng., vol. 8, no. 5, pp. 1319-1324, 2020, doi: 10.35940/ijrte.e6176.018520.

[76] Y. C. Chiou, H. Y. Chou, and M. Y. Shen, "Effects of adding graphene nanoplatelets and nanocarbon aerogels to epoxy resins and their carbon fibre composites," Mater. Des., vol. 178, p. 107869, 2019, doi: 10.1016/j.matdes.2019.107869.

[77] Q. Meng et al., "Mechanically robust, electrically and thermally conductive graphene-based epoxy adhesives," J. Adhes. Sci. Technol., vol. 33, no. 12, pp. 1337-1356, 2019, doi: 10.1080/01694243.2019.1595890.

[78] K. A. Imran and K. N. Shivakumar, "Graphene-modified carbon/epoxy nanocomposites: Electrical, thermal and mechanical properties,” J. Compos. Mater., vol. 53, no. 1, pp. 93-106, 2019, doi: 10.1177/0021998318780468.

[79] M. Nazmus Sakib, A. A. Iqbal, and D. M. Nuruzzaman, "Mechanical characterisation of carbon fibre and graphene oxide reinforced epoxy hybrid composite.," in Recent Trends in Manufacturing and Materials Towards Industry 4.0, Singapore: Lecture Notes in Mechanical Engineering. Springer, 2021, pp. 155-161.

[80] K. Kumar, P. K. Ghosh, and A. Kumar, "Improving mechanical and thermal properties of TiO2-epoxy nanocomposite," Compos. Part B Eng., vol. 97, pp. 353-360, 2016, doi: 10.1016/j.compositesb.2016.04.080.

[81] W. Zhai et al., "Preparation of epoxy-acrylate copolymer@nano-TiO2 Pickering emulsion and its anti-bacterial activity," Prog. Org. Coatings, vol. 87, pp. 122-128, Oct. 2015, doi: 10.1016/j.porgcoat.2015.05.019.

[82] E. R. Ghomi et al., "Synthesis and characterisation of TiO2/acrylic acid-co-2-acrylamido-2-methyl propane sulfonic acid nanogel composite and investigation its self-healing performance in the epoxy coatings," Colloid Polym. Sci., vol. 298, no. 2, pp. 213-223, Feb. 2020, doi: 10.1007/s00396-019-04597-0.

[83] J. L. H. Chau, C. T. Tung, Y. M. Lin, and A. K. Li, "Preparation and optical properties of titania/epoxy nanocomposite coatings," Mater. Lett., vol. 62, no. 19, pp. 3416-3418, Jul. 2008, doi: 10.1016/j.matlet.2008.02.058.

[84] N. Farhadyar and M. S. Sadjadi, "Synthesis and characterisation of ZnO-SiO2/epoxy nanocomposite coating by sol-gel process," J. Nano Res., vol. 16, no. 2011, pp. 1-8, 2012, doi: 10.4028/www.scientific.net/JNanoR.16.1.

[85] G. V. Seretis, I. D. Theodorakopoulos, D. E. Manolakos, and C. G. Provatidis, "Effect of sonication on the mechanical response of graphene nanoplatelets/glass fabric/epoxy laminated nanocomposites," Compos. Part B Eng., vol. 147, no. April, pp. 3341, 2018, doi: 10.1016/j.compositesb.2018.04.034.

[86] S. J. Park, F. L. Jin, and C. Lee, "Preparation and physical properties of hollow glass microspheres-reinforced epoxy matrix resins," Mater. Sci. Eng. A, vol. 402, no. 1-2, pp. 335-340, 2005, doi: 10.1016/j.msea.2005.05.015.

[87] F. Mustata, N. Tudorachi, and D. Rosu, "Thermal behavior of some organic/inorganic composites based on epoxy resin and calcium carbonate obtained from conch shell of Rapana thomasiana," Compos. Part B Eng., vol. 43, no. 2, pp. 702-710, Mar. 2012, doi: 10.1016/j.compositesb.2011.11.047.

[88] M. Heimann, M. Wirts-Ruetters, B. Boehme, and K. J. Wolter, "Investigations of carbon nanotubes epoxy composites for electronics packaging," in Proceedings - Electronic Components and Technology Conference, 2008, pp. 1731-1736, doi: 10.1109/ECTC.2008.4550214.

[89] M. Izadi, T. Shahrabi, and B. Ramezanzadeh, "Active corrosion protection performance of an epoxy coating applied on the mild steel modified with an eco-friendly sol-gel film impregnated with green corrosion inhibitor loaded nanocontainers," Appl. Surf. Sci., vol. 440, pp. 491-505, May 2018, doi: 10.1016/j.apsusc.2018.01.185.

[90] G. Suriati, M. Mariatti, and A. Azizan, "Effects of filler shape and size on the properties of silver filled epoxy composite for electronic applications," J. Mater. Sci. Mater. Electron., vol. 22, no. 1, pp. 56-63, Jan. 2011, doi: 10.1007/s10854-010-00822.

[91] H. B. Ustaołlu et al., "Static and dynamic analysis of plastic fuel tanks used in buses," in Procedia Engineering, Jan. 2015, vol. 101, no. C, pp. 509-517, doi: 10.1016/j.proeng.2015.02.061. 
[92] J. Mathew, J. Joy, and S. C. George, "Potential applications of nanotechnology in transportation: A review,” J. King Saud Univ. - Sci., vol. 31, no. 4, pp. 586-594, 2019, doi: 10.1016/j.jksus.2018.03.015.

[93] M.-P. Todor and I. Kiss, "Systematic approach on materials selection in the automotive industry for making vehicles lighter, safer and more fuel-efficient," Appl. Eng. Lett., vol. 1, no. 4, pp. 2466-4847, 2016, [Online]. Available: http://oaji.net/articles/2017/3807-1486245278.pdf.

[94] S. Modi and A. Vadhavkar, Technology Roadmap : Materials and Manufacturing. Michigan USA, 2019.

[95] E. Ghassemieh, "Materials in automotive application, state of the art and prospects," New Trends Dev. Automot. Ind., 2011, doi: $10.5772 / 13286$.

[96] M. K. Kulekci, "Magnesium and its alloys applications in automotive industry," Int. J. Adv. Manuf. Technol., vol. 39, no. 910, pp. 851-865, Nov. 2008, doi: 10.1007/S00170-007-1279-2.

[97] A. Dziubińska, A. Gontarz, M. Dziubiński, and M. Barszcz, "The forming of magnesium alloy forgings for aircraft and automotive applications," Adv. Sci. Technol. Res. J., vol. 10, no. 31, pp. 158-168, 2016, doi: 10.12913/22998624/64003.

[98] C. Blawert, N. Hort, and K. U. Kainer, "Automotive application of magnesium and its alloys," Trans. Indian Inst. Met., vol. 57, no. 4, pp. 397-408, 2004.

[99] M. K. Kulekci, "Magnesium and its alloys applications in automotive industry," Int. J. Adv. Manuf. Technol., vol. 39, no. 910, pp. 851-65, 2008, doi: 10.1007/s00170-007-1279-2.

[100] W. S. Miller et al., "Recent development in aluminium alloys for the automotive industry," Mater. Sci. Eng. A, vol. 280, no. 1, pp. 37-49, Mar. 2000, doi: 10.1016/S0921-5093(99)00653-X.

[101] I. N. Fridlyander et al., "Aluminum alloys: Promising materials in the automotive industry," Met. Sci. Heat Treat., vol. 44, no. 9-10, pp. 365-370, 2002, doi: 10.1023/A:1021901715578.

[102] R. Chandel, N. Sharma, and S. A. Bansal, "A review on recent developments of aluminum-based hybrid composites for automotive applications," Emergent Mater., 2021, doi: 10.1007/s42247-021-00186-6.

[103] M. A. Fentahun and M. A. Savas, "Materials used in automotive manufacture and material selection using ashby charts," Int. J. Mater. Eng., vol. 8, no. 3, pp. 40-54, 2018, doi: 10.5923/j.ijme.20180803.02.

[104] C. Saricam and N. Okur, "Polyester usage for automotive applications," in Polyester - Production, Characterisation and Innovative Applications, N. Onar Camlibel, Ed. Pamukkale University, Turkey: IntechOpen, 2018, pp. 69-85.

[105] ACC, "Plastics and polymer composites technology roadmap for automotive markets," Am. Chem. Counc., no. March, pp. 158, 2014, [Online]. Available: https://www.google.com/url?sa=t\&rct=j\&q=\&esrc=s\&source=web\&cd=1\&ved= 0ahUKEwjvhaCNjrnMAhWGn5QKHWk5DMgQFggvMAA\&url=https://plastics-car.com/TomorrowsAutomobiles/Plastics-and-Polymer-Composites-Technology-Roadmap/Plastics-and-Polymer-Composites-Technology-R.

[106] J. Agarwal, S. Sahoo, S. Mohanty, and S. K. Nayak, "Progress of novel techniques for lightweight automobile applications through innovative eco-friendly composite materials: A review," J. Thermoplast. Compos. Mater., vol. 33, no. 7, pp. 9781013, 2020, doi: 10.1177/0892705718815530.

[107] M. Peters, J. Hemptenmacher, J. Kumpfert, and C. Leyens, "Structure and properties of titanium and titanium alloys," in Titanium and Titanium Alloys, Wiley-VCH Verlag GmbH \& Co. KGaA, 2005, pp. 1-36.

[108] D. L. Singaravelu, R. R. M., V. R., S. Manoharan, and M. Kchaou, "Development and performance evaluation of eco-friendly crab shell powder based break pads for automotive applications," Int. J. Automot. Mech. Eng., vol. 16, no. 2, pp. 6502-6523, 2019.

[109] D. Chan and G. W. Stachowiak, "Review of automotive brake friction materials," Proc. Inst. Mech. Eng. Part D J. Automob. Eng., vol. 218, no. 9, pp. 953-966, Sep. 2004, doi: 10.1243/0954407041856773.

[110] C. Seubert et al., "An overview of the scratch resistance of automotive coatings: exterior clearcoats and polycarbonate hardcoats," Coatings, vol. 2, no. 4, pp. 221-234, Nov. 2012, doi: 10.3390/coatings2040221.

[111] F. Lei et al., "Facile design and fabrication of highly transparent and hydrophobic coatings on glass with anti-scratch property via surface dewetting," Prog. Org. Coatings, vol. 120, pp. 28-35, Jul. 2018, doi: 10.1016/j.porgcoat.2018.03.008.

[112] S. Das et al., "A review on superhydrophobic polymer nanocoatings: recent development and applications," Industrial and Engineering Chemistry Research, vol. 57, no. 8. American Chemical Society, pp. 2727-2745, Feb. 28, 2018, doi: 10.1021/acs.iecr.7b04887.

[113] A. Sobczyk-Guzenda et al., "Bactericidal and photowetting effects of titanium dioxide coatings doped with iron and copper/fluorine deposited on stainless steel substrates," Surf. Coatings Technol., vol. 347, pp. 66-75, Aug. 2018, doi: 10.1016/j.surfcoat.2018.04.067.

[114] M. A. Sardou, E. E. Damotte, C. Zunino, and P. Djomseu, "Light weight, low cost, composite coil springs are a reality," SAE Technical Paper 2005-01-1698, 2005, doi: 10.4271/2005-01-1698.

[115] P. Eiamchai et al., "Designs and investigations of anti-glare blue-tint side-view car mirrors," Mater. Des., vol. 31, no. 7, pp. 3151-3158, Aug. 2010, doi: 10.1016/j.matdes.2010.02.033.

[116] S. Kugler, K. Kowalczyk, and T. Spychaj, "Transparent epoxy coatings with improved electrical, barrier and thermal features made of mechanically dispersed carbon nanotubes," Prog. Org. Coatings, vol. 111, pp. 196-201, Oct. 2017, doi: 10.1016/j.porgcoat.2017.05.017.

[117] R. J. Hand, B. Ellis, B. R. Whittle, and F. H. Wang, "Epoxy based coatings on glass: Strengthening mechanisms," J. Non. Cryst. Solids, vol. 315, no. 3, pp. 276-287, Jan. 2003, doi: 10.1016/S0022-3093(02)01611-3.

[118] M. Mohseni, B. Ramezanzadeh, H. Yari, and M. Moazzami, "The role of nanotechnology in automotive industries," New Adv. Veh. Technol. Automot. Eng., pp. 3-54, 2012, doi: 10.5772/49939.

[119] K. Sehanobish, Engineering Plastics and Plastic Composites in Automotive Applications. SAE International, 2009.

[120] L. N. Shafigullin et al., "Development of a polymeric fuel tank with high barrier properties," IOP Conf. Ser. Mater. Sci. Eng. Pap., vol. 570, no. 2019, p. 012088, 2019, doi: 10.1088/1757-899X/570/1/012088.

[121] L. N. Shafigullin et al., "Usage of polymeric fuel tanks in the automotive industry," IOP Conf. Ser. Mater. Sci. Eng. Pap., vol. 412, no. 2018, p. 012071, 2018, doi: 10.1088/1757-899X/412/1/012071.

[122] "Epoxy resin market size \& share | industry report, 2024." [Online]. Available: https://www.grandviewresearch.com/industryanalysis/epoxy-resins-market [Accessed: Nov. 14, 2020].

[123] B. Ravishankar, S. K. Nayak, and M. A. Kader, "Hybrid composites for automotive applications - A review," Journal of Reinforced Plastics and Composites, vol. 38, no. 18. pp. 835-845, 2019, doi: 10.1177/0731684419849708. 
[124] "Steel versus aluminium: who's winning the lightweighting battle in cars? - Aluminium Insider." [Online]. Available: https://aluminiuminsider.com/steel-versus-aluminium-whos-winning-lightweighting-battle-cars/ [Accessed: Feb. 25, 2021].

[125] G. Mago et al., "Polymer nanocomposite processing, characterisation, and applications 2013," J. Nanomater., vol. 2014, 2014, doi: $10.1155 / 2014 / 403492$. 